\title{
Singing, Yeast, and Diesel Fuel Capture Video Prize
}

\author{
The top video prize from the APS Division of Fluid Dynamics showcased \\ research inspired by the pandemic, moving yeast, and the need for better \\ fuel efficiency.
}

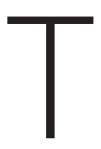
he APS Division of Fluid Dynamics has announced the 2020 winners of its annual Gallery of Fluid Motion video and poster contest. Below are the video winners of the Milton van Dyke Award, which recognizes the three top videos and the three top posters.

\section{Opera Singer's Airflow}

During this pandemic, it isn't easy to be a singer. Singing can effectively spread the virus that causes COVID-19, so a team of researchers studied airflow during singing in order to help the Metropolitan Opera orchestra determine guidelines for a safe work environment.

Howard Stone of Princeton University and his colleagues used an infrared camera to image airflow near a singer's mouth and a

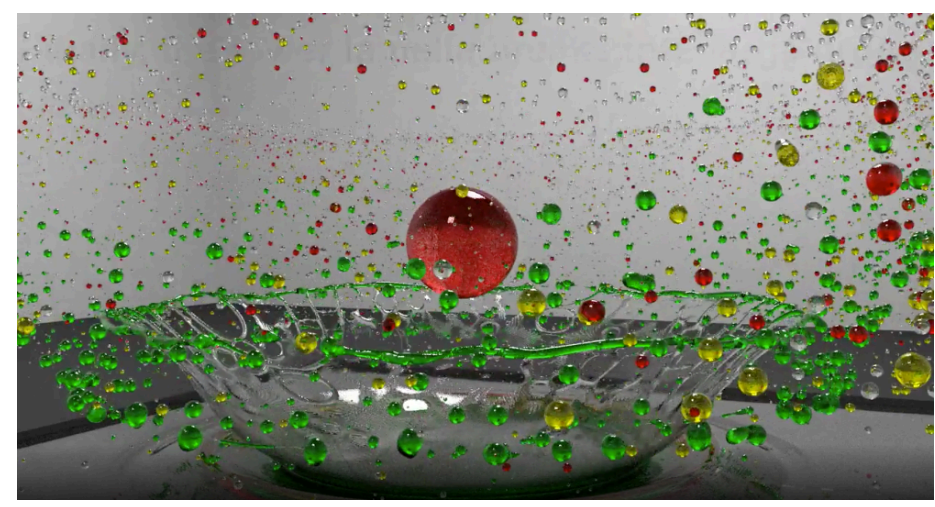

A frame from one of the Gallery of Fluid Motion award-winning videos shows a simulation of droplets of diesel fuel produced by the splashing of larger drops impacting a solid, horizontal surface. Credit: D. Markt et al./Univ. of Mass., Dartmouth/Michigan Tech./Argonne National Lab

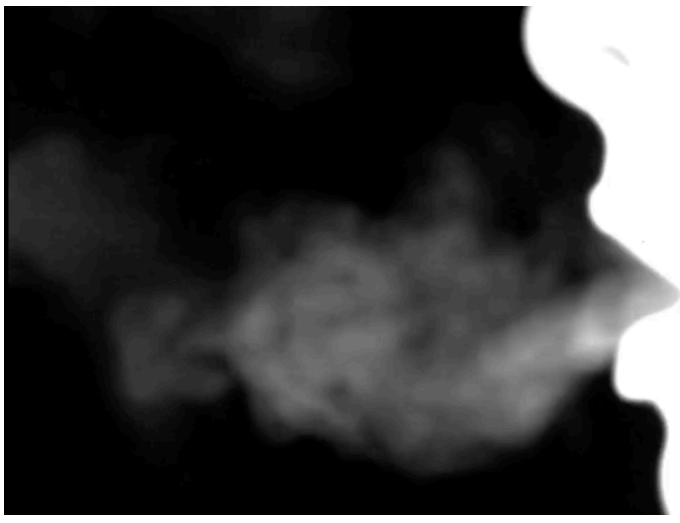

Researchers used infrared imaging of carbon dioxide to produce a video showing the airflow from an opera singer's mouth. Credit: P. Bourrianne et al./Princeton Univ./Univ. of Montpellier

flow meter to track the volume of air expelled per second. First, the team imaged and measured themselves while singing, breathing, or speaking, and found that singing produced more airflow than speaking.

Next, the team turned the camera and flow meter on professional opera singer Isabel Leonard. Compared with the amateurs, Leonard's airflow during singing was less than during speaking and was also more controlled. "It's amazing to see how the singer is able to impose a constant flow rate, whereas if you speak, there are a lot of fluctuations," says Princeton team member Philippe Bourrianne. The team continues to observe both singers and wind instrumentalists in their lab and expects to provide data that will inform decisions regarding distancing between performers and ventilation techniques. 


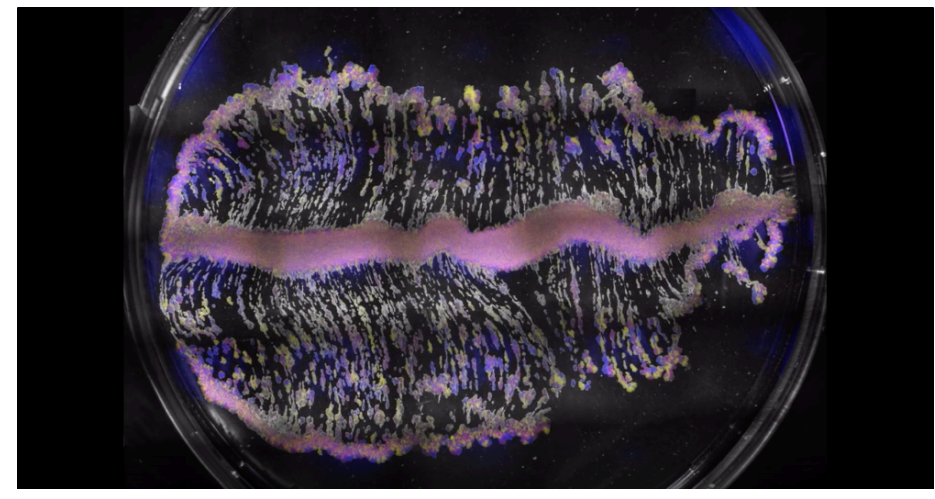

The metabolism of yeast growing on a viscous liquid generates fluid flows that tear the colony apart.

Credit: S. Atis et al./Univ. of Chicago/Harvard Univ.

\section{Yeast in Motion}

Yeast in the lab "smells really good," says Severine Atis, of the University of Chicago, "like fresh bread or beer." Like a lot of researchers, Atis studies yeast cells-which divide every hour or so-because they can rapidly reveal the effects of natural selection. Atis and her Harvard University colleagues wanted to observe clumps of yeast cells (colonies) growing in a liquid because life began in the ocean, not in a gel like that found in a typical petri dish. To allow colonies to grow normally on a liquid, Atis developed a high-viscosity growth medium.

But then "biology did something we were not expecting," Atis recalls. Under certain conditions, parts of the colony would slowly drift away, which was strange, because the team thought that the high viscosity would prevent any fluid flow. The team ultimately realized that, as a floating colony metabolizes glucose, it creates a low-glucose and thus low-density region of fluid underneath. When this volume tries to spread out across the liquid surface, it generates a convection flow that pulls the growing colony apart, as the team reported last year (see Viewpoint: Microbial Expansion Shaped by Fluid Flows). The team is considering the possibility that the spreading behavior is an evolutionary adaptation that allows groups of cells to move toward regions with more nutrients.

Before she left Harvard for Chicago, Atis thought about proposing an exhibit of yeast images at a local brewpub. The display "would be very fitting, especially in the Cambridge-Boston area, because people who go to local

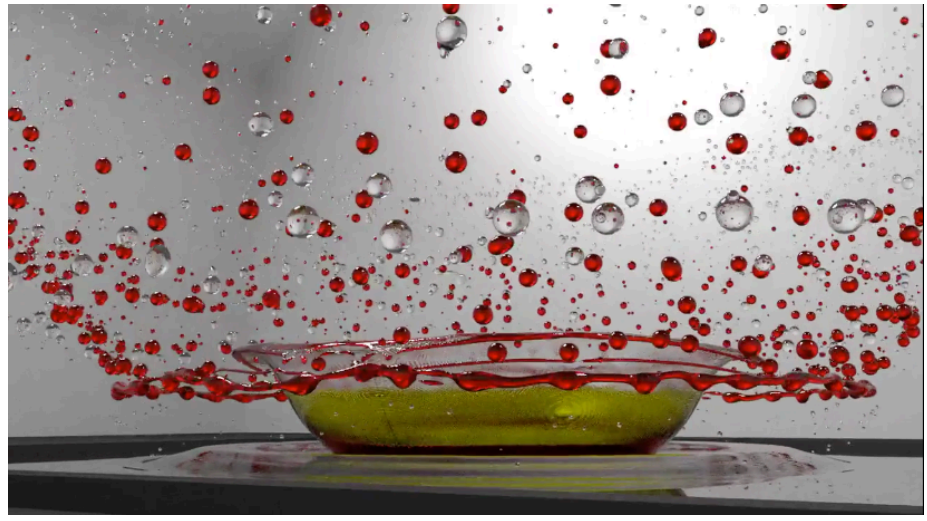

In this simulation, diesel fuel drops splash upon impact with a surface and create secondary droplets, modeling fuel injection into an engine's combustion chamber.

Credit: D. Markt et al./Univ. of Mass., Dartmouth/Michigan Tech./Argonne National Lab

breweries there are all geeks, and they all want to know about the science."

\section{A Splash of Diesel Fuel}

"My jaw was on the floor," recalls Mehdi Raessi, of the University of Massachusetts, Dartmouth, describing the first time he saw a simulation of splashing diesel fuel produced by David Markt, his graduate student. He was impressed by the lifelike beauty of the movies, which showed fuel drops hitting a surface and producing secondary droplets.

Raessi and Markt's work is aimed at helping engine manufacturers better simulate the events inside of a combustion chamber. The manufacturers use so-called submodels of various elements of the process, but current submodels of fuel injection don't accurately capture the splashing of injected fuel and the resulting tiny droplets. Manufacturers want these secondary droplets to be as small as possible, which reduces the amount of leftover fuel after combustion and improves efficiency.

The videos are so realistic that they often lead to confusion, says Markt. Despite being honest about the sources of the videos, "anytime l've presented these results, I've had audience members that come up to me and ask if these images were 
experimental."

- David Ehrenstein and Ruma Arabatti

David Ehrenstein is the Focus Editor for Physics, and Ruma
Arabatti is a Physics science writing intern. 